\title{
Diaphragm electromyography results at different high flow nasal cannula flow rates
}

\author{
Eleanor Jeffreys $^{1,2} \cdot$ Katie A Hunt ${ }^{1,2} \cdot$ Theodore Dassios $^{1,3} \cdot$ Anne Greenough $^{1,2,3,4}$ (D) \\ Received: 10 April 2019 / Revised: 19 May 2019 / Accepted: 21 May 2019 / Published online: 11 June 2019 \\ (C) The Author(s) 2019
}

\begin{abstract}
Heated, humidified, high-flow nasal cannula (HHHFNC) is increasingly being used, but there is a paucity of evidence as to the optimum flow rates in prematurely born infants. We have determined the impact of three flow rates on the work of breathing (WOB) assessed by transcutaneous diaphragm electromyography (EMG) amplitude in infants with respiratory distress or bronchopulmonary dysplasia (BPD). Flow rates of 4, 6 and $8 \mathrm{~L} / \mathrm{min}$ were delivered in random order. The mean amplitude of the EMG trace and mean area under the EMG curve (AEMGC) were calculated and the occurrence of bradycardias and desaturations recorded. Eighteen infants were studied with a median gestational age of 27.8 (range 23.9-33.5) weeks and postnatal age of 54 (range 3-122) days. The median flow rate prior to the study was 5 (range 3-8) L/min and the fraction of inspired oxygen $\left(\mathrm{FiO}_{2}\right)$ was 0.29 (range $0.21-0.50$ ). There were no significant differences between the mean amplitude of the diaphragm EMG and the AEGMC and the number of bradycardias or desaturations between the three flow rates.

Conclusions: In infants with respiratory distress or BPD, there was no advantage of using high $(8 \mathrm{~L} / \mathrm{min})$ compared with lower flow rates (4 or $6 \mathrm{~L} / \mathrm{min}$ ) during support by HHHFNC.

What is known:

- Humidified high flow nasal cannulae (HHHFNC) is increasingly being used as a non-invasive form of respiratory support for prematurely born infants.

- There is a paucity of evidence regarding the optimum flow rate with 1 to $8 \mathrm{~L} / \mathrm{min}$ being used.

What is new:

- We have assessed the work of breathing using the amplitude of the electromyogram of the diaphragm at three HHHFNC flow rates in infants with respiratory distress or $B P D$.

- No significant differences were found in the EMG amplitude results or the numbers of bradycardias or desaturations at 4, 6 and 8 L/min.
\end{abstract}

Keywords High flow nasal cannula $\cdot$ Diaphragm $\cdot$ Electromyogram

$\begin{array}{ll}\text { Abbreviations } \\ \text { AEMGC } & \text { Area under the EMG curve } \\ \text { BPD } & \text { Bronchopulmonary dysplasia } \\ \text { EMG } & \text { Electromyogram } \\ \mathrm{FiO}_{2} & \text { Fraction of inspired oxygen }\end{array}$

Communicated by Patrick Van Reempts

Anne Greenough

anne.greenough@kcl.ac.uk

Eleanor Jeffreys

Eleanor.jeffreys@nhs.net

Katie A Hunt

Katie.a.hunt@kcl.ac.uk

Theodore Dassios

Theodore.dassios@kcl.ac.uk
HHHFNC Heated, humidified, high-flow nasal cannula nCPAP Nasal continuous positive airway pressure RCT Randomised controlled trial $\mathrm{SaO}_{2} \quad$ Oxygen saturation level 


\section{Introduction}

There is increasing use of non-invasive ventilation for prematurely born infants. This includes nasal continuous positive airway pressure (nCPAP) and heated, humidified, high flow nasal cannula (HHHFNC). A systematic review of randomised controlled trials (RCTs) has shown that HHHFNC may be at least an equivalent to nCPAP [20]. A UK survey [16], however, showed that the flow rates used during HHHFNC were variable, from 1 to $8 \mathrm{~L} / \mathrm{min}$. Similarly, in Canada [4], starting flow rates ranged from 1 to $6 \mathrm{~L} / \mathrm{min}$ and maximal flow rates were from 2 to $8 \mathrm{~L} / \mathrm{min}$.

There have been studies determining the effect of flow rate on the pressure generated during HHFNC. In an in vitro model, airway pressure was shown to increase with increasing HHFNC flow rates [17], but HHFNC cannula systems could generate uncontrolled CPAP levels and mouth leaks affected the CPAP level [3]. An in vivo study highlighted a linear increase in positive pharyngeal pressure as flow rates during HHHFNC increased from 2 to $8 \mathrm{~L} / \mathrm{min}$ [21]. Similarly, in another study, a significant association between flows and generated oesophageal pressures was demonstrated, but with variability in the amount of end expiratory pressure generated [5]. Furthermore, a linear relationship between measured pharyngeal pressure and flow rates was seen using either of the two HHFNC devices [1]. A further study demonstrated increasing flow rates led to increasing intrapharyngeal pressures [18]. It might then be expected that increasing flow rates might reduce the work of breathing (WOB). There is, however, a paucity of conflicting evidence regarding how different flow rates of HHHFNC affect the work of breathing. In one study [15], no significant differences in the work of breathing were demonstrated between flow rates of 3,4 , or $5 \mathrm{~L} / \mathrm{min}$ during HHHFNC and nCPAP delivered at $6 \mathrm{~cm} \mathrm{H}_{2} \mathrm{O}$. In another study, however, compared to a baseline of nCPAP of $6 \mathrm{~cm}$ $\mathrm{H}_{2} \mathrm{O}$, respiratory rates increased when the infants were transferred to HHFNC at $6 \mathrm{~L} / \mathrm{min}$ and the flow rate was reduced by $1 \mathrm{~L} / \mathrm{min}$ every $30 \mathrm{~min}$ suggesting that WOB had increased [10]. In prematurely born infants, an increased WOB in infants can lead to respiratory acidosis, an increased oxygen requirement and failure to thrive. Thus, it is important to determine if different flow rates during HHFNC do affect the WOB.

There is increased respiratory drive when the work of breathing increases. Neural respiratory drive can be assessed by measuring the electromyogram (EMG) of the diaphragm.

The EMG of the diaphragm can now be measured transcutaneously by placing electrodes on the skin overlying the diaphragm [2]. This non-invasive technique has been shown to be well tolerated by infants and yields reproducible results [7].

We hypothesised that at higher flow rates of HHHFNC, there might be higher lung volumes due to the increased pressures and hence a lower WOB and more effective support as assessed by lower levels of desaturations and bradycardias. The aim of this study was to test that hypothesis by determining whether there was a reduction in the work of breathing as assessed by the amplitude of the diaphragm EMG as the flow rate of HHHFNC was increased over the range 4 to $8 \mathrm{~L} / \mathrm{min}$ in prematurely born infants with respiratory distress or bronchopulmonary dysplasia (BPD). In addition, we wished to determine if higher compared to lower flow rates were associated with fewer bradycardias and desaturations.

\section{Methods}

A randomised cross-over study was conducted at a tertiary neonatal unit in King's College Hospital NHS Foundation Trust between March and August 2018. The study was approved by the Wales Research Ethics Committee and parents gave written informed consent for their infant to take part. Prematurely born infants of less than or equal to 34 weeks of gestational age who were already on HHHFNC with respiratory distress or BPD were eligible for the study. BPD was diagnosed if the infant was oxygen-dependent for 28 days after birth [6].

HHHFNC was delivered either by an Optiflow device (Fisher and Paykel Healthcare, New Zealand) or an SLE 6000 ventilator (SLE limited, Croydon UK). The nasal prongs (Fisher and Paykel Healthcare, New Zealand) used were chosen such that they occluded less than half the nares, but not the whole of the nares [21]. We did not ensure that the infant's mouth was closed during the study period as we wished to assess the effect of the different flow rates as they are used in routine clinical practice. The infants received HHHFNC at three flow rates of $4 \mathrm{~L} / \mathrm{min}, 6 \mathrm{~L} / \mathrm{min}$ and $8 \mathrm{~L} / \mathrm{min}$, each for $1 \mathrm{~h}$. The order in which the flow rates were delivered to an infant was determined by a random number generator.

Infants were routinely monitored throughout the study. The $\mathrm{FiO}_{2}$ was altered to maintain oxygen saturations between 92 and $96 \%$. Bradycardias were recorded if the heart rate fell below $100 \mathrm{bpm}$ for more than $3 \mathrm{~s}$ and a desaturation if the oxygen saturation level $\left(\mathrm{SaO}_{2}\right)$ fell below $88 \%$ for more than $3 \mathrm{~s}$. Three seconds was chosen so that no artefactual data were included. The study was stopped if a change in flow rate was not tolerated as evidenced by a greater than 0.1 increase in $\mathrm{F}_{\mathrm{i}} \mathrm{O}_{2}$ or there was a bradycardia which lasted more than $10 \mathrm{~s}$ or a desaturation for longer than $10 \mathrm{~s}$. Patient characteristics collected included gestational age at birth, postnatal age, birth weight, exposure to antenatal steroids and postnatal surfactant and the pre-study flow rate and $\mathrm{FiO}_{2}$.

The transcutaneous diaphragm EMG was monitored using a portable 16-channel digital physiological amplifier (Dipha16; Inbiolab, Groningen, the Netherlands) and three surface electrodes (Kendall H59P cloth electrodes; Covidien, 
Massachusetts). The method used to filter the electric activity of the heart was similar to the gating technique described by O'Brien [13]. The device wirelessly transmitted to a bedside computer running Polybench (Applied Biosignals, Weener, Germany). The diaphragm EMG was started at the beginning of the study and recorded continuously throughout the $3 \mathrm{~h}$. Data were analysed from the last $5 \mathrm{~min}$ of each hour to allow for acclimatisation of the infant to each new flow rate.

EMG data were imported into MATLAB from Poly5 format using the TMSi MATLAB Interface (Twente Medical Systems International, Oldenzaal, the Netherlands). A range of time frames for analysis have been used previously ranging from $30 \mathrm{~s}$ to $1 \mathrm{~min}[7,8]$. The first $50 \mathrm{~s}$ artefact-free time frame within the last $5 \mathrm{~min}$ of each hour was selected, as it was the maximum time frame for all infants without interference. The mean amplitude of the EMG trace (as a measure of the motor unit activity) and the mean area under the EMG curve (AEMGC) as previously described [2] were calculated (Fig. 1) using MATLAB Statistics Toolbox Release 2015b, (The MathWorks, Inc., Natick, MA, USA).

\section{Analysis}

Differences between the three groups were assessed using the Friedman test or chi-square test as appropriate. Post hoc pairwise analysis with Bonferroni correction was carried out if statistically significant differences were found across the three levels. SPSS Statistics Version 24 was used.

\section{Sample size}

Eighteen infants allowed detection between flow rates of one standard deviation in the mean EMG amplitude $(1.65 \mathrm{mV}$, $40 \%$ of the AEMGC) with $80 \%$ power at the $5 \%$ significance level.

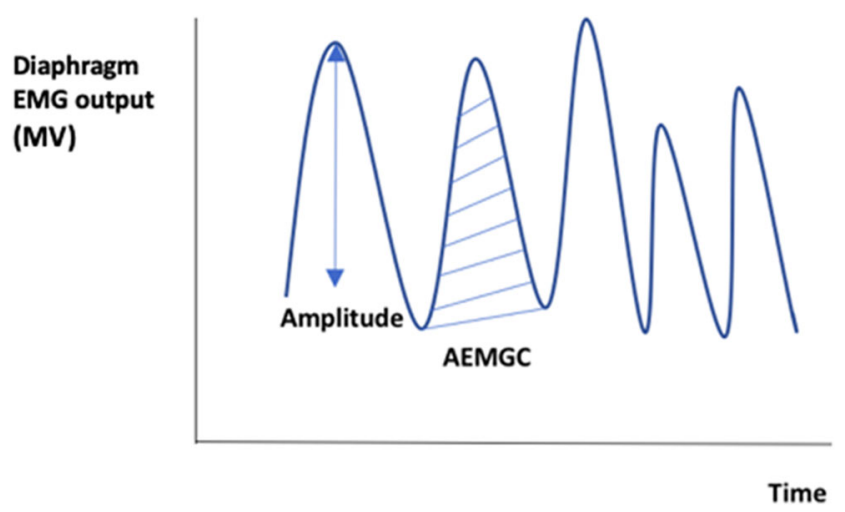

Fig. 1 Representation of diaphragm EMG curve showing the amplitude (shown by the vertical line) and area under the curve (AEMGC) (shown by the hatched area)

\section{Results}

Eighteen infants with a median birthweight of 992 (range 555-2380) g, a median gestational age of 27.8 (range 23.933.5 ) weeks and a median postnatal age of 54 (range 3-122) days were studied. Five had respiratory distress and 13 had BPD. Their median flow rate immediately prior to the study was 5 (range 3-8) $\mathrm{L} / \mathrm{min}$ and their median $\mathrm{F}_{\mathrm{i}} \mathrm{O}_{2}$ was 0.29 (range $0.21-0.50$ ). Thirteen infants had been exposed antenatally to corticosteroids and 17 had been given surfactant postnatally. In none of the infants was the study stopped prematurely.

There were no significant differences between the diaphragm EMG amplitude (Fig. 2) $(p=0.678)$ or the AEGMC $(p=0.946)$ between the three flow rates (Table 1). Equally, the lowest EMG amplitude experienced at the different flow rates did not differ significantly according to levels being in six infants at $4 \mathrm{~L} /$ $\min$, five at $6 \mathrm{~L} / \mathrm{min}$ and seven at $8 \mathrm{~L} / \min (p=0.778)$ and the smallest AEMGC was experienced by five infants at $4 \mathrm{~L} / \mathrm{min}$, five at $6 \mathrm{~L} / \mathrm{min}$ and eight at $8 \mathrm{~L} / \mathrm{min}$ $(p=0.472)$. There were also no significant differences in the number of bradycardias $(p=0.368)$ or desaturations $(p=0.276)$ between the three flow rates (Table 1).

\section{Discussion}

We have demonstrated that there were no significant differences in the diaphragmatic EMG amplitude between three flow rates during HHHFNC, nor did we see any significant differences in the proportions of infants with the lowest EMG amplitudes or AEGMC between the three different flow rates. Furthermore, we also assessed the occurrence of bradycardias or desaturations and found no significant differences at the three flow rates. Our findings are consistent with that of Saslow et al. [15] who showed no change in distending pressure between three flow rates of HHHFNC, but they used a smaller range of flow rates of three to $5 \mathrm{~L} / \mathrm{min}$.

The lack of significant differences between our three groups may reflect the variable pressure delivered during HHHFNC. Although, in one study, a linear increase in pharyngeal pressure as flow rate increased was demonstrated, independent of whether the mouth was open or closed; in another [9], no positive pressure was generated while the oral cavity was open. We did not ensure the infant's mouth was closed during the study as we wished to examine the effect of different flow rates as used in routine clinical practice and hence our results would be generalizable.

There are strengths and some limitations to our study. Three flow rates were assessed in each infant thus, although the infants recruited had a wide range of postnatal ages, they 


\section{in}

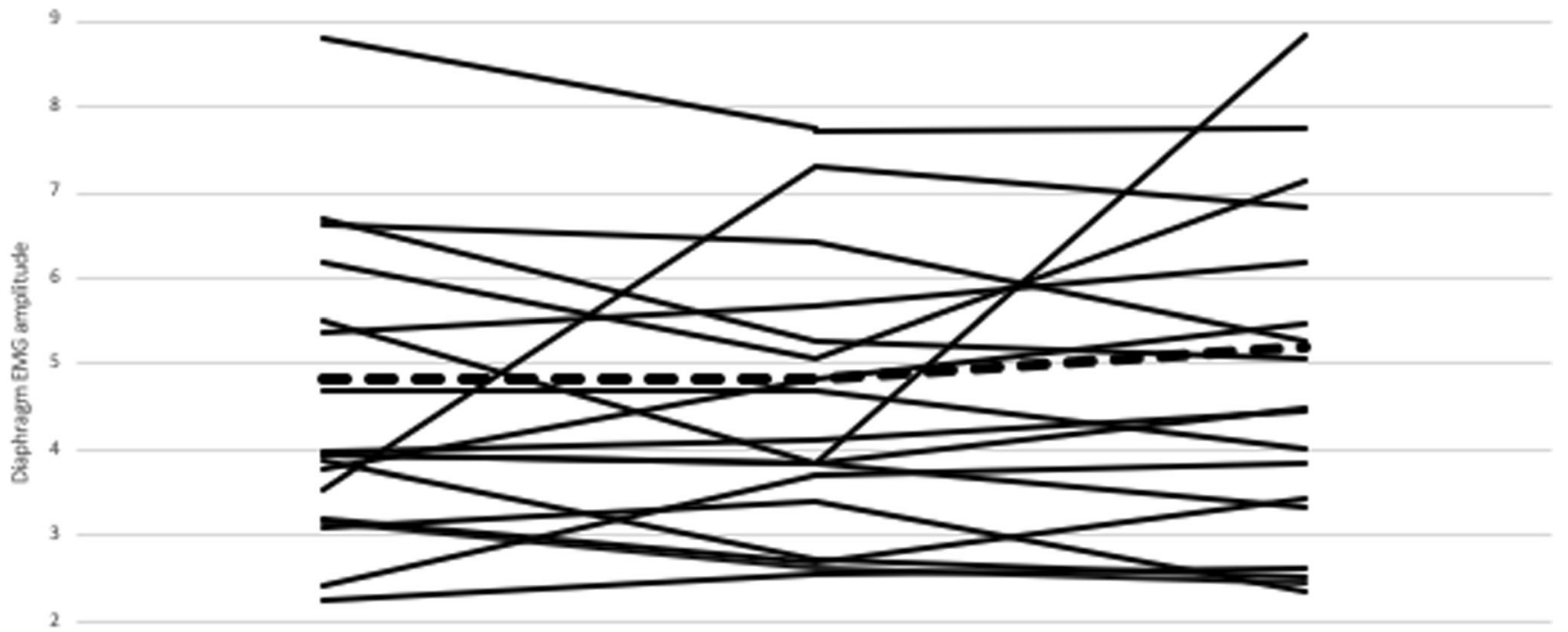

Fig. 2 Diaphragm EMG amplitude plotted against the three flow rates. Each individual's data points are linked and the average of all the infants' data shown by the dashed line

each acted as their own controls. The median $\mathrm{FiO}_{2}$ immediately before recruitment to the study suggested that some of the infants had mild disease, but there was a range of $\mathrm{FiO}_{2}$ levels. Indeed, the infants were typical of those on our NICU who receive HHHFNC and similar to those on other units [16]. We have included a figure of the individual data which demonstrates there was no obvious trend according to the results according to flow rate amongst infants with respiratory distress of evolving or established BPD. Differences in skin contact and anatomical differences between infants can cause variability in the results obtained, yet as seen in Fig. 2, the majority of infants resulted in the same manner to the three flow levels. We have not included in our study infants with very severe respiratory failure, as in our experience, such

Table 1 Diaphragm EMG amplitude, AEMGC, desaturations and bradycardias at the three flow rates. Data are displayed as median (range) or $n$

\begin{tabular}{llll}
\hline & $4 \mathrm{~L} / \mathrm{min}$ & $6 \mathrm{~L} / \mathrm{min}$ & $8 \mathrm{~L} / \mathrm{min}$ \\
\hline Amplitude (mV) & $3.96(2.25-8.80)$ & $4.00(2.57-7.75)$ & $4.47(2.36-8.82)$ \\
AEMGC (mVs) & $1.62(1.15-3.44)$ & $1.74(1.15-3.48$ & $1.86(1.06-3.74)$ \\
Desaturations & 8 & 6 & 5 \\
Bradycardias & 1 & 1 & 0 \\
\hline
\end{tabular}

infants are not routinely supported by HHFNC. We did not measure $\mathrm{CO}_{2}$ levels as the infants did not have indwelling arterial lines. We recorded $\mathrm{FiO}_{2}$ changes as highlighted by the number of desaturations and did not show any significant differences according to the flow rate. The diaphragmatic EMG was assessed transcutaneously as previously reported [2]. This technique only assesses the electrical activity of the frontal diaphragm and not the intercostal muscles [12]. In preterm infants, however, the intercostal muscles are not thought to have a substantial contribution to breathing effort during tidal breathing [19]. Furthermore, this technique has demonstrated that weaning from CPAP to low flow nasal cannula led to an increase in diaphragmatic activity measured by EMG and was most prominent in preterm infants who failed the weaning attempt [7]. We assessed the diaphragmatic EMG which acts as a surrogate of the work of breathing and has been shown to differ between infants receiving no respiratory support and those on HHHFNC at $6 \mathrm{~L} / \mathrm{min}$ [14]. The amplitude of the diaphragm EMG, however, may not be fully representative of the work of breathing, but in addition to assessing the diaphragm EMG, we also examined the occurrence of desaturations and bradycardias and demonstrated no significant differences in those outcomes between the three flow rates. Our results are consistent with those of de Waal et al. [2] who suggested that different HHHFNC flow 
rates in stable infants do not influence work of breathing as assessed by the neural respiratory drive.

In conclusion, we have demonstrated that in prematurely born infants with respiratory distress or BPD, there were no statistically significant differences in the amplitude of the diaphragm EMG or the numbers of desaturations or bradycardias at three different levels of HHHFNC. We have not undertaken a sub-analysis according to underlying diagnosis, as our sample size highlights such a sub-analysis would be underpowered. Our individual results, however, show similar results in all infants. These results suggest there may be no overall advantages of using high compared to lower flow rates. We suggest practitioners should individualise the HHHFNC level taking into account the severity of the infants' lung disease using the $\mathrm{FiO}_{2}$ level and objectively assess the effect of different flow rates by recording $\mathrm{FiO}_{2}$ changes and the number of desaturations and bradycardias.

Acknowledgements We are grateful to Dr. Ian Hunt who assisted in writing the MATLAB code for the analysis and Mrs. Deirdre Gibbons for secretarial assistance.

Authors' Contributions AG co-designed the study and was involved in analyzing the data and the production of the manuscript.

$\mathrm{KH}$ co-designed the study, collected the data and was involved in the analysis of the data and production of the manuscript.

EJ collected the data and was involved in the analysis of the data and production of the manuscript.

TD was involved in the analysis of the data and the production of the manuscript.

Funding The research was supported by the National Institute for Health Research (NIHR) Biomedical Research Centre based at Guy's and St Thomas' NHS Foundation Trust and King's College London.

Compliance with ethical standards All procedures performed in studies involving human participants were in accordance with the ethical standards of the institutional and/or national research committee and with the 1964 Helsinki declaration and its later amendments or comparable ethical standards.

Conflict of interest AG has held grants from various manufacturers (Abbot Laboratories, MedImmune) and ventilator manufacturers (SLE). Professor Greenough has received honoraria for giving lectures and advising various manufacturers (Abbot Laboratories, MedImmune) and ventilator manufacturers (SLE). Professor Greenough is currently receiving a non-conditional educational grant from SLE.

Informed consent Parents gave informed written consent.

Disclaimer The views expressed are those of the author(s) and not necessarily those of the NHS, the NIHR, or the Department of Health.

Open Access This article is distributed under the terms of the Creative Commons Attribution 4.0 International License (http:// creativecommons.org/licenses/by/4.0/), which permits unrestricted use, distribution, and reproduction in any medium, provided you give appropriate credit to the original author(s) and the source, provide a link to the Creative Commons license, and indicate if changes were made.

\section{References}

1. Collins CL, Hoberton JR, Konig K (2013) Comparison of the pharyngeal pressure provided by two heated humidified high flow nasal cannulae devices in premature infants. J Pediatr Child Health 49: $554-556$

2. de Waal CG, Hutten GJ, Kraaijenga JV, de Jongh FH, van Kaam AH (2017) Electrical activity of the diaphragm during nCPAP and high flow nasal cannula. Arch Dis Child Fetal Neonatal Ed 102: F434-F438

3. Hasan RA, Habib RH (2011) Effects of flow rate and airleak at the nares and mouth opening on positive distending pressure delivery using commercially available high flow nasal cannula systems: a lung model study. Pediatr Crit Care Med 12:e29-e33

4. Hochwald O, Osiovich H (2010) The use of high flow nasal cannulae in neonatal intensive care units: is clinical practice consistent with the evidence? J Neonatal-Perinatal Med 3:187-191

5. Iyer NP, Mhanna MJ (2016) Association between high flow nasal cannula and end expiratory esophageal pressures in premature infants. Respir Care 61:285-290

6. Jobe AH, Bancalari E (2001) Bronchopulmonary dysplasia. Am J Respir Crit Care Med 163:1723-1729

7. Kraaijenga JV, Hutten GJ, de Jongh FH, van Kaam AH (2015) Transcutaneous electromyography of the diaphragm: a cardiorespiratory monitor for preterm infants. Pediatr Pulmonol 50:889895

8. Kraaijenga JV, Hutten GJ, de Jongh FH, van Kaam AH (2015) The effect of caffeine on diaphragmatic activity and tidal volume in preterm infants. J Pediatr 167:70-75

9. Kubicka ZJ, Limauro J, Darnall RA (2008) Heated, humidified high-flow nasal cannula therapy: yet another way to deliver continuous positive airway pressure? Pediatrics 121:82-88

10. Lampland AL, Plumm B, Meyers PA, Worwa CT, Mammel MC (2009) Observational study of humidified high flow nasal cannula compared with nasal continuous positive airway pressure. J Pediatr 154:177-182

11. Lavizzari A, Veneroni C, Colnaghi M, Ciuffini F, Zannin E, Fumagalli M, Mosca F, Dellaca RL (2014) Respiratory mechanics during nCPAP and HHHFNC at equal distending pressures. Arch Dis Child Fetal Neonatal Ed 99:F315-F320

12. Maarsingh EJ, van Eykern L, Sprikkelman AB, Hoekstra MO, van Aalderen WM (2000) Respiratory muscle activity measured with a noninvasive EMG technique: technical aspects and reproducibility. J Appl Physiol 88:1955-1961

13. O'Brien MJ, van Eykern LA, Prechtl H (1983) Monitoring respiratory activity in infants: a nonintrusive diaphragm EMG technique. Noninvasive Physiological Measurements, London, Academic 2: 131-177

14. Oda A, Parikka V, Lehtonen L, Porres I, Soukka H (2019) Nasal high flow therapy decreased electrical activity of the diaphragm in preterm infants during the weaning phase. Acta Paediatr 108:253257

15. Saslow JG, Aghai ZH, Nakhla TA, Hart JJ, Lawrysh R, Stahl GE, Pyon KH (2006) Work of breathing using high-flow nasal cannula in preterm infants. J Perinatol 26:476-480

16. Shetty S, Sundaresan A, Hunt K, Desai P, Greenough A (2016) Changes in the use of humidified high flow nasal cannula oxygen. Arch Dis Child Fetal Neonatal Ed 101:F371-F372 
17. Sivieri EM, Gerdes JS, Abbasi S (2013) Effect of HFNC flow rate, cannula size and nares diameter on generated airway pressures: an in vitro study. Pediatr Pulmonol 48:506-514

18. Spence KL, Murphy D, Kilian C, McGonigle R, Kilani RA (2007) High flow nasal cannula as a device to provide continuous positive airway pressure in infants. J Perinatol 27:772-775

19. Taylor A (1960) The contribution of the intercostal muscles to the effort of respiration in man. J Physiol 151:390-402

20. Wilkinson D, Andersen C, O’Donnell CP, De Paoli AG, Manley BJ (2016) High flow nasal cannula for respiratory support in preterm infants. Cochrane Database Syst Rev (2):CD006405
21. Wilkinson DJ, Andersen CC, Smith K, Holberton J (2008) Pharyngeal pressure with high-flow nasal cannulae in premature infants. J Perinatol 28:42-47

Publisher's note Springer Nature remains neutral with regard to jurisdictional claims in published maps and institutional affiliations. 